\title{
An innovation diffusion model for new mobile technologies acceptance
}

\author{
Nadi Barkoczia ${ }^{1}$, Elena Simina Lakatos ${ }^{1,2, *}$ and Laura Andrada Bacali ${ }^{1}$ \\ ${ }^{1}$ Faculty of Machine Building, Technical University of Cluj-Napoca, 400641 Cluj-Napoca, Romania \\ ${ }^{2}$ Center for Innovation and Organizational Sustainability, Cluj-Napoca 400609, Romania
}

\begin{abstract}
This paper aims to approach the diffusion model developed in 1960 by Frank Bass has been utilized to study the distribution of different types of new products and services. The Bass Model helps by describing the process in which new products are adopted in a market. This model is a useful tool for predicting the first purchase of an innovative product for which there are competing alternatives on the market. It also provides the innovator with information regarding the size of customers and the adoption time for the product. The second part of the paper is dedicated to a monographic study of specific conceptual correlations between the diffusion of technology and marketing management that emphasizes technological uncertainty and market uncertainty as major risks to innovative projects. In the final section, the results of empirical research conducted in Baia-Mare, Romania will be presented in a way that uses diffusion Bass model to estimate the adoption period for new mobile technologies.
\end{abstract}

\section{Introduction}

The present study aims to emphasize the interferences of technology diffusion and marketing management by using one part of the mathematical Bass model. The research questions of the study are: How does interpersonal relations influence new technology adopting speed? Depending on the time needed for the new technology to be adopted, is it possible to predict the lifecycle of new product?

According to recent studies, the percentage of innovation failure varies from 5\% to $90 \%$ depending on the nature of innovation and target customers [1]. Additional sources assume that $97 \%$ of new ideas and prototypes for new products enter the market and more than half of those fail within two years [2]. Anticipating success of the new product or service is therefore one of the most demanding tasks in critical management [3].

Currently, a significant number of empirical studies have been devoted to the diffusion of innovation. Impressive results have been achieved both in the theoretical and practical fields. Creating models for marketing purposes is an essential part of the so-called new marketing strategy [4].

\footnotetext{
${ }^{*}$ Corresponding author: simina.lakatos@mis.utcluj.ro
} 
Information and communication technology facilitates the collection and recording of data. Analytical software enables fast and efficient data processing. However, new products forecast diffusion in comparison to well implemented processes that have certain limits to [3]: The limited availability of historical data on sales; Lack of knowledge about new markets which causes a high risk for producers and other members of the distribution channel. Section 2 of the paper is dedicated to a literature review of international technology and the diffusion of technology. It approaches interferences between the diffusion of technology and sourcing of marketing. Section 3 of the paper contains the methodology for empirical research and the data analysis followed by a presentation of the results Section 4. These sections are dedicated to the measurement of the first purchase of an innovative product for which competing alternatives exist on the market. It provides the innovator with information regarding the size of customers and the adoption time for the product. The last section provides the conclusions and theoretical and practical implications of the study. Technology continues to become a competitive instrument that is increasingly important for many organizations [5].

\section{Current stage of research regarding diffusion in marketing}

The research in the diffusion field seeks to understand innovation distribution through their life cycle modelling and from a consumers' interaction point of view [6]. Danciu [7] emphasizes the fact that both adaptation, such as permanent and progressive innovations of marketing and business, will be placed in the center of solutions that must be adopted as a consequence of the impact of evolutions and tendencies of the environment. One of the distinctive tendencies is the substantial shortening of the product life cycle. The shortest life cycle suggests a faster and faster entering of products on the global market and the disappearance of products that maintain for a long time their position on the market [8].

Each type of technology is followed by the apparition of new products. Specifically, products that rapidly progress through their life cycle [9]. Due to rapidly recorded technological progress, some specialists consider conventional theories about a products life cycle somehow obsolete. This is the result of shortened life cycles, consumers' change in lifestyle, and a rapid process of continuous change that characterizes the industry, such as the entire economy [10]. Beginning with the 90 's, diffusion modelling in specialized literature has seeked to extend the Bass framework with the aim of reflecting on the complexity of a new product. Recent contributions to diffusion modelling research has reexamined this interpretation to identify and discuss about other social types of interaction $[11,12]$. Clark and Goldsmith [13] examine the relationship between innovation and social influence (interpersonal) that can manifest either as normative influence or informational influence. The variable factors were analyzed separtely, although in the marketing research they are considered part of a global concept named consumer susceptibility to interpersonal influence.

\section{Methodology}

\subsection{Bass Model Description}

The Bass model was developed by Frank M. Bass [14] and has been widely used for new product forecasting. The main point in the Bass model is about adoption and diffusion of innovative products or technology. The Bass Curve formula is approximated by the following equation in discrete time: 


$$
n(t)=p *[M-N(t-1)]+\frac{q}{M} * N(t-1) *[M-N(t-1)]
$$

$\mathrm{n}(\mathrm{t})=$ number of new buyers of the product or service concerned when $\mathrm{t}$

$\mathrm{N}(\mathrm{t}-1)=$ cumulative number of buyers at time $\mathrm{t}-1$

$\mathrm{M}=$ the potential market, i.e., the total number of potential buyers of the final product that should be set to launch.

$p=$ the coefficient of innovation or external influence that characterizes the probability that a person who has not yet used the product begins to use it due to external influence in the process of dissemination: advertising, price, product awareness in the media, personal needs and ease of use.

$\mathrm{q}=$ the coefficient of imitation or internal influence characterizes the probability that a person who has not yet used the product begins to use it due to the influence of those who are already using the product. With a total of three points available for parameter estimation, equation 1 reduces to:

$$
n(t)=\alpha_{1}+\alpha_{2} * N(t-1)+\alpha_{3} * N^{2}(t-1)
$$

where: $\alpha_{1}=\mathrm{p} * \mathrm{~m}, \mathrm{p}$ and $\mathrm{q} \alpha_{2}=\alpha_{3}=\mathrm{q} / \mathrm{m}$.

When $q$ is greater than $p$, sales of innovation increases to a peak and then declines. When $q$ is less than $p$, sales decrease monotonically. When $q$ is 0 , the model reduces to an exponential low. It is interesting to note that the exponential distribution is a variant of the Bass diffusion model by taking the parameter $q=0$, i.e. considering only the category of innovators to identify new buyers. When $\mathrm{p}=0$, identical to the model Bass Mansfield.

To estimate the values of $p, q$ and $m$ of equation (1) Bass model we can find time $T$ when adopting its peak. It is given by [15]:

$$
T(\text { peak })=\frac{1}{(p+q) \times \ln \frac{q}{p}} \mathrm{~V}
$$

Equations (1) and (3) are the most relevant. They allow us to anticipate how long it takes to adopt a new technology which is at the peak of its adoption.

\subsection{Data analysis}

We conducted a study based on the survey research method with its instrument, the questionnaire, to gather information from users about mobile technology with the aim of estimating the adoption period of new mobile products with the use of the Bass Model. Through the use of ordinary least square and the nonlinear regression method based on historical data, we estimate the parameters $\mathrm{p}$, $\mathrm{q}$ and $\mathrm{m}$. We also intended to investigate the changes of the model forecasting under different analogous products. We chose our subjects applying a non-random sampling, based on affordability.

The survey focuses on tracking the process of the diffusion of new technologies in the mobile market. The questionnaire provides information about consumers' behavior on the mobile phone market. Also, it includes personal information (gender, age, profession, income) requited to identify the target group. We applied a total number of 328 questionnaires taking into consideration three age categories (16-21, 22-30 and 30+). For this research we chose people between 22 and 30 years of age which are considered the most representative for applying the Bass model of technology diffusion, totaling 164 respondents. The questionnaire was administrated and implemented by the authors. The implementation period was between March 1, 2014 and August 31, 2014. The target group is represented by the consumers in the mobile phone market from Baia-Mare, Romania. 


\section{Results}

According to the questionnaire on the technology diffusion for mobile phone products, we used the Bass model in terms of determining the number of new adopters of mobile products and the period of time required for adoption in the context of respondents between 22 and 30 years, separately for women and men. We considered all 164 respondents as potential adopters (Table 1). The research we made is divided into three parts:

a. Predicting the adoption of new technologies for $M=70$ women, respectively $M=94$ men aged 22 to 30 years of age;

b. Forecasting the period for all 164 respondents to adopt;

c. Conducting a comparative study of the male and female adopters aged between 22 and 30 years of age.

Table 1. Estimating the potential market $M$, the innovation coefficients $p$ and the imitation coefficients q.

\begin{tabular}{|l|l|l|l|}
\hline Potential adopters & M & p & $\mathrm{q}$ \\
\hline Women aged 22 to 30 years & 70 & 0,09 & 0,50 \\
\hline Men aged 22 to 30 years & 94 & 0,15 & 0,37 \\
\hline
\end{tabular}

In the beginning, we estimated the values for the $\mathrm{p}$ and $\mathrm{q}$ parameters. These values were estimated using the answers given by the respondents to question 12 in the questionnaire, "If you were interested in purchasing, what information sources would you use?", whose answers allowed us to divide the respondents into two categories of adopters: innovators and imitators. The following step was to estimate the two coefficients for innovation (p) and imitation (q). Thus, the data needed for implementing the Bass mathematical model is found in the table below. Regarding the new male adopters, of the 94 potential adopters at time $\mathrm{t}=1$, we have a number of 14 new adopters, representing innovators, and at time $\mathrm{t}=2$, we have a number of 16 new adopters of which 12 are innovators and 4 imitators, and so on. As it can be seen from the data given in the 2 tables during the period of adoption, initially we only have innovators and only external influence factors on potential adopters are present.

Table 2. Determining the number of new females and respectively male adopters at the time t.

\begin{tabular}{|c|c|c|c|c|c|c|c|c|c|c|}
\hline \multirow[b]{2}{*}{$\mathbf{t}$} & \multicolumn{5}{|c|}{ Women } & \multicolumn{5}{|l|}{ Men } \\
\hline &  & $\stackrel{\overparen{I}}{\underline{Z}}$ & 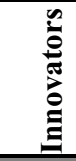 & 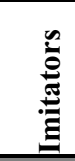 & $\bigoplus_{\Xi}$ & 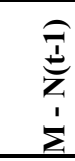 & $\stackrel{\overparen{I}}{\underline{z}}$ & 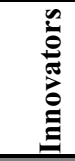 & & 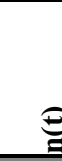 \\
\hline 0 & 70 & 0 & & & & 94 & 0 & & & \\
\hline 1 & 64 & 6 & 6 & 0 & 6 & 80 & 14 & 14 & 0 & 14 \\
\hline 2 & 55 & 15 & 6 & 3 & 9 & 63 & 31 & 12 & 4 & 16 \\
\hline 3 & 44 & 26 & 5 & 6 & 11 & 46 & 48 & 10 & 8 & 17 \\
\hline 4 & 32 & 38 & 4 & 8 & 12 & 31 & 63 & 7 & 9 & 16 \\
\hline 5 & 21 & 49 & 3 & 9 & 12 & 18 & 76 & 5 & 8 & 12 \\
\hline 6 & 11 & 59 & 2 & 7 & 9 & 10 & 84 & 3 & 5 & 8 \\
\hline 7 & 6 & 64 & 1 & 5 & 6 & 5 & 89 & 2 & 3 & 5 \\
\hline 8 & 3 & 67 & 1 & 3 & 3 & 3 & 91 & 1 & 2 & 3 \\
\hline 9 & 1 & 69 & 0 & 1 & 1 & 1 & 93 & 0 & 1 & 1 \\
\hline 10 & 0 & 70 & 0 & 1 & 1 & 1 & 93 & 0 & 0 & 1 \\
\hline
\end{tabular}


Once the new technology was brought to the attention of potential adopters by innovators, imitators appear and thus along the diffusion process of new technologies, the number of innovators gradually decreases while the number of imitators increases. The women adoption period is 10 weeks and for men it is the same.

In Figure 1, we plotted the cumulative adoption of new technologies in time and the period required for adoption of the 70 women respondents and 94 men respondents, both categories within the interval of 22 and 30 years of age.

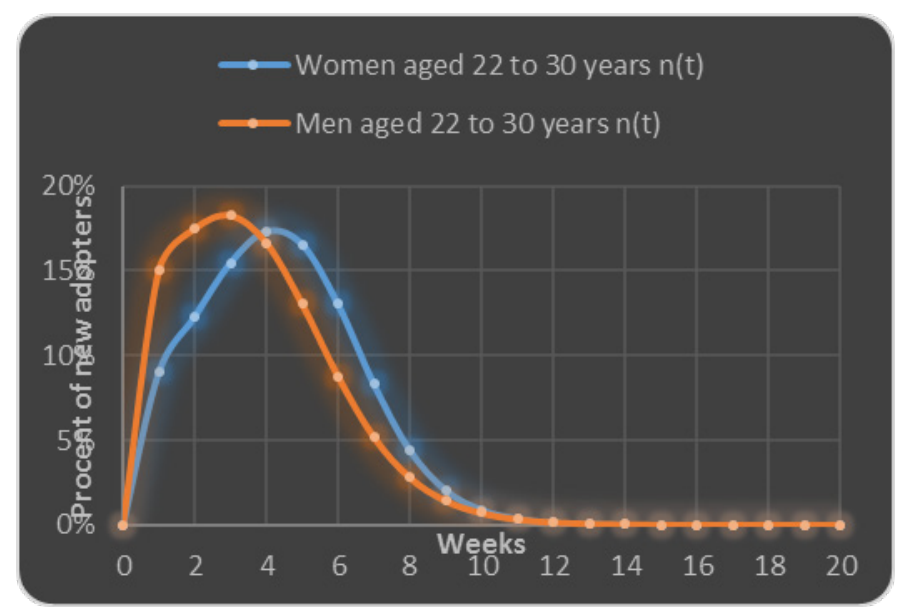

Fig. 1. The adoption period for women and respectively men.

Also, the number of imitators is higher among women, the coefficient of imitation is $\mathrm{q}=$ 0,50 compared to 0,37 in men. Regarding the number of new adopters $n(t)$ at time $t=1$, it is 6 for females compared to 14 for male adopters.

\section{Conclusions and discussions}

In this paper, we conducted a monographic study of specific conceptual correlations between the diffusion of technology and industrial marketing management. On one hand, and an empirical analysis of adopters' behavior regarding a new technology on the mobile phone market using Bass technology diffusion model. We cannot approach the product life cycle without an analysis of consumer's behavior. In the introduction and growth phases, the most innovative consumers will adopt the product. In the maturity phase, more and more cautious consumers will buy the product until a new product with more performance based features will appear and the consumers will move towards the new product. The fundamental problem for marketing specialists is the assessment of maturity phase duration. Regarding the empirical analysis we concluded that:

- Male consumers are more under the influence of external factors than women. This is explained by the greater value of the innovation coefficient (p). On the mobile phone market, they are more open to new technologies.

- The internal factors have a greater influence on women. The imitation coefficient (q) is higher on women.

- The number of imitators within the category of age 22 to 30 years is zero at first, then increases rapidly to reach a peak and then decreases when there are fewer people who have not yet bought the new product. 
- The coefficient of innovators (p) for men is higher than for women, which is due to the external influence, being stronger on men than on women. It can also be noticed that the imitation coefficient (q) has a higher value for women than for men which explain that women are more opened to word-of-mouth communication.

This study requires more investigation into the further implementation of the Bass mathematical model of diffusion in new technologies by addressing the lifecycle of products on the mobile market and notice the differences in adopting new technologies by the different categories of age and gender, but also other individual characteristics such as culture, financial affordability, level of education, etc. The comparative analysis of the results obtained will be useful for the formulation of future marketing strategies.

"This work was undertaken through the Partnerships in Priority Domains: Programmer -PN II, developed with the support of MEN-UEFISCDI, Project no.337/2014 - UNIINOI".

\section{References}

1. V. Trommsdorff, Marketing inovací. Nakladatelství CH Beck (2009)

2. N. Barkoczi, M. Lobonţiu, L. Bacali, Review of Management \& Economic Engineering, 14 (2), 297 (2015)

3. M. Vasil'ová, Conceptual Framework and Research Propositions for Modeling the Diffusion of Technological Innovation. Marketing-trends-congress (2012)

4. P. S. Leeflang, D. R. Wittink, International journal of research in marketing, 17 (2), 105 (2000)

5. L. Dovleac, Launching Efforts Needed For A High-Tech Product. Management \& Marketing-Craiova, (1), 149 (2011)

6. R. Peres, E. Muller, V. Mahajan, International Journal of Research in Marketing, 27 (2), 91 (2010)

7. V. Danciu, Marketingul viitorului, răspunsul adecvat la schimbările mediului. Economie teoretică şi aplicată, 27 (2013)

8. B. Kim, Managing the transition of technology life cycle. Technovation, 23 (5), 371 (2003)

9. E. Viardot, Successful marketing strategy for high-tech firms. Artech House, (2004)

10. M. C. Demetrescu, Metode de analiză în marketing. Teora, (2001)

11. C. I. Ivanov, S. Avasilcăi, Procedia - Social and Behavioral Sciences, 124, 397 (2014)

12. L.I. Cioca, and M. Cioca, WSEAS Transactions on Information Science and Applications 4 (2), 303 (2007)

13. R. A. Clark, R. E. Goldsmith, Journal of Marketing Theory and Practice, 14 (4), 275 (2006)

14. F. M. Bass, Management Sci 15 (5), 215 (1969)

15. D. R. Firth, C. Lawrence, S. F. Clouse, Interdisciplinary Journal of Information, Knowledge, and Management 1 (1), 1 (2006) 